\title{
Erratum to: Screening of Ginger Germplasm for Resistance to Rhizome Rot
}

\author{
Pratap Keshari Pattnaik • Dattatreya Kar • \\ Ananya Kuanar · Budhadev Mishra
}

Published online: 13 February 2014

(C) The National Academy of Sciences, India 2014

Erratum to: Proc. Natl. Acad. Sci., India, Sect. B Biol.

\section{Sci DOI 10.1007/s40011-013-0272-9}

In the original publication, first and last author names were misspelt. The correct names are given in this erratum.

The online version of the original article can be found under doi: 10.1007/s40011-013-0272-9.

P. K. Pattnaik · B. Mishra Department of Plant Pathology, Orissa University of Agriculture and Technology, Surya Nagar, Bhubaneshwar 751003, Odisha, India

e-mail: pratapouat@gmail.com

D. Kar $(\varangle) \cdot$ A. Kuanar

Centre of Biotechnology, Siksha O Anusandhan University, Kalinga Nagar, Ghatikia, Bhubaneswar 751003, Odisha, India

e-mail: kardattatreya@gmail.com 